\title{
Rancang Bangun E-Reporting Pada Bagian Pelayanan PDAM Kabupaten Kuningan Berbasis Image Geotagging
}

\author{
Iwan Lesmana*1, ${ }^{2}$ Reny Hernawati ${ }^{2}$, Fahmi Yusuf ${ }^{3}$ \\ Universitas Kuningan \\ *11wanlesmana@uniku.ac.id,2renyherna26@gmail.com, 3․ahmionline@uniku.ac.id,
}

\begin{abstract}
ABSTRAK
Perusahaan Daerah Air Minum (PDAM) Kabupaten Kuningan merupakan salah satu perusahaan daerah Kabupaten Kuningan. PDAM bergerak dalam penyediaan air minum bagi masyarakat yang dalam operasionalnya melekat dua fungsi, yaitu sebagai unsur pelayanan masyarakat dan sebagai salah satu sumber PAD. Dalam proses pelayanan pelanggan yang sedang berjalan saat ini pada sistem pendaftaran pemasangan air bersih PDAM dan pengaduan keluhan, pelanggan datang ke kantor PDAM terdekat atau menelepon via whatsapp. Perlu adanya sebuah sistem untuk mengefektifkan dan mengefisienkan itu semua. Dalam pembangunan sistem, penulis menggunakan metode waterfall sebagai metode pengembangan sistem. Sistem yang dibangun dapat membantu PDAM Tirta Kamuning untuk proses pemasangan air PDAM, proses pengaduan keluhan pelanggan, mengelola data user, mengelola data pemasangan air PDAM, mengelola data pengaduan keluhan dan pelaporan. Konsep Geotagging di pergunakan pada saat pelanggan melaporkan pengaduan kerusakan dengan mengupload foto yang berisi data EXIF, dimana data tersebut diolah untuk dijadikan mapping atau untuk mengetahui lokasi pelanggan. Sistem pelayanan yang dibuat menggunakan dua platform. Untuk frontend menggunakan android yang mencakup proses pemasangan air PDAM, proses pengaduan keluhan dan informasi perusahaan. Sedangkan untuk backend menggunakan Web Based yang mencakup pengelolaan data pelanggan, data admin dan data teknisi, memverifikasi data pemasangan air PDAM dan data pengaduan keluhan, serta pengelolaan laporan.
\end{abstract}

Kata kunci : PDAM Kuningan, Pengaduan, Android, Geotagging, PHP

\begin{abstract}
PDAM Tirta Kamuning is one of the regional companies in Kuningan Regency. The company provides drinking water for the society. Operationally, it has two functions, as community service and as one of PAD sources. However, the current system of customer services is considered too old or unsophisticated. It includes the process of servicing new installation and responding customer complaint is through direct visit by customer visit to the closest PDAM office or calls the officer through phone or WhatsApp. To help renewing the system, this research is developing waterfall method system to overcome the problem in PDAM Tirta Kamuning. This system development is intended to improve the service of new installation of PDAM, customer complaint, data management, data of PDAM installation, and customer complain report. The Geotagging concept used when a customer reports a complaint by uploading a photo containing EXIF data, and then, the data is processed by seeing the customer's location through map. This system applies two platforms. First, the front end is using android, and it includes the process of installing PDAM, the process of complaints and company information. Second platform, the backend, is using Web Based which regulates customer data management, admin data and technician data, verifies the installation of PDAM and complaint data, and management reports.
\end{abstract}

Keywords: PDAM Kuningan, Complaint, android, Geotagging, PHP 


\section{PENDAhuluan}

Perkembangan teknologi dan informasi saat ini berkembang dengan sangat pesat. Teknologi perangkat bergerak smartphone menjadi kebutuhan yang sudah sangat erat dalam kehidupan sehari-hari. Smartphone sebagai media komunikasi yang memiliki berbagai macam fitur, juga fleksibel dapat dibawa ke mana saja dan kapan saja serta memiliki 'user-friendly interface'. Pada perangkat bergerak smartphone, sensor kamera dan GPS sudah menjadi fitur dasar. Salah satu implementasi dari sensor kamera dan GPS adalah geotagging yang merupakan teknologi untuk memberikan keterangan berbasis lokasi pada media digital yang diambil melalui smartphone. Teknologi geotagging banyak diimplementasikan pada jejaring sosial untuk menampilkan dimana lokasi suatu foto diambil sehingga pengguna dapat berbagi informasi secara lebih mendetail.[1]

Perkembangan tersebut mampu merambah semua segi kehidupan manusia, sehingga memudahkan kita dalam melakukan berbagai macam aktifitas. Perkembangan penduduk yang semakin meningkat tentu akan menimbulkan berbagai permasalahan yang juga berpengaruh di dalam permasalahan pelayanan terhadap masyarakat.[2] Kebutuhan akan urusan pelayanan publik merupakan hal yang sangat penting bagi masyarakat. Tuntutan akan bentuk pelayanan yang cepat, efektif dan efisien sangat dibutuhkan oleh masyarakat. Demikian juga dalam hal pengaduan masyarakat terhadap peristiwa yang ada di sekitar lingkungan mereka yang bersifat mendesak, hal tersebut membutuhkan tindakan dari pihak-pihak yang bersangkutan dan mempunyai tanggung jawab dalam penyelesaian masalah tersebut.
Perusahaan Daerah Air Minum (PDAM) Kabupaten Kuningan merupakan salah satu perusahaan daerah yang dimiliki oleh Pemerintah Daerah. PDAM Kabupaten Kuningan bergerak dalam penyediaan air minum bagi masyarakat yang dalam operasionalnya melekat dua fungsi, yaitu sebagai unsur pelayanan masyarakat dan sebagai salah satu sumber PAD.[3] Perusahaan Daerah Air Minum Tirta Kamuning ini memiliki 10 kantor cabang dan 1 kantor pusat. Proses bisnis yang terjadi di PDAM Tirta Kamuning Kabupaten Kuningan pada bagian pelayanan masih dilakukan secara konvensional baik dalam proses pendaftaran pemasangan air bersih PDAM ataupun proses pengaduan keluhan pelanggan. Dengan kata lain calon pelanggan harus mendatangi kantor Perusahaan Daerah Air Minum Tirta Kamuning terdekat untuk melakukan pendaftaran pemasangan air bersih dan pelanggan melaporkan via SMS, menelepon via whatsapp atau datang langsung ke kantor PDAM terdekat jika ingin melakukan pengaduan. Keluhan pelanggan yang sering terjadi adalah keluhan mengenai air macet, kebocoran pipa, air kotor, dan tagihan rekening air yang membengkak. Mekanisme tersebut kurang optimal karena sering terjadinya keterlambatan pemasangan atau perbaikan dan kesalahan dalam pencarian lokasi kerusakan.

Penelitian ini bertujuan untuk mengefektifkan waktu dan mengefisienkan biaya dalam proses pemasangan air PDAM dan proses pengaduan keluhan pelanggan serta dapat membantu teknisi dalam pencarian lokasi pengadu.

Manfaat dari penelitian ini adalah dapat merespon pendaftaran pemasangan air bersih PDAM dan memperbaiki kebocoran pipa, air macet, air kotor dan tagihan rekening air yang 
membengkak dengan cepat sesuai dengan laporan pelanggan.

\section{METODE PENELITIAN}

Metode penelitian yang digunakan dalam menyelesaikan penelitian ini, yaitu:

\subsection{Metode Pengumpulan Data}

Adapun metode pengumpulan data yang dilakukan yaitu:

\subsubsection{Wawancara}

Wawancara dilakukan dengan bagian pelayanan PDAM Tirta Kamuning Kabupaten Kuningan untuk mencari data yang dibutuhkan untuk pembuatan sistem informasi ini.

\subsubsection{Observasi}

Observasi dilakukan dengan cara datang dan mengamati proses-proses yang terjadi di PDAM Tirta Kamuning Kabupaten Kuningan dan mengambil beberapa foto sebagai bentuk dokumentasi dari observasi yang telah dilakukan.

\subsubsection{Studi Literatur}

Studi literatur dilakukan dengan mengumpulkan data yang relevan dengan penelitian yang dilakukan. Data tersebut diperoleh darti e-book, jurnal, internet dan buku.

\subsection{Metode Pengembangan Sistem}

Metode air terjun atau yang sering disebut metode waterfall dinamakan siklus hidup klasik (classic life cycle), dimana hal ini menggambarkan pendekatan yang sistematis dan juga berurutan pada pengembangan perangkat lunak, dimulai dengan spesifikasi kebutuhan pengguna lalu berlanjut melalui tahapan-tahapan perencanaan (planning), permodelan (modeling), konstruksi (construction), serta penyerahan sistem ke para pelanggan/pengguna (deployment), yang diakhiri dengan dukungan pada perangkat lunak lengkap yang dihasilkan.[4]

Untuk lebih jelasnya tahapan metode waterfall dapat dilihat pada Gambar 1 .

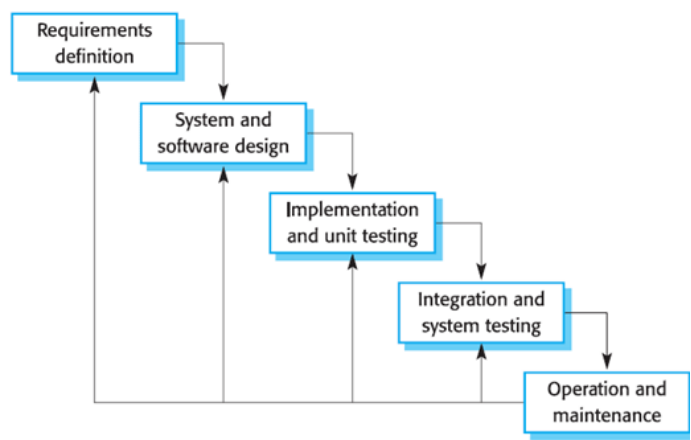

Gambar 1. Metode Waterfall.

\subsubsection{Requirement Definition}

Pada tahap ini dilakukan wawancara dengan Bagian Pelayanan PDAM untuk mendapatkan data yang berkaitan dengan masalah pendaftaran pemasangan air bersih PDAM pengaduan keluhan pelanggan.

\subsubsection{System and Software Design}

Proses desain yang dibuat meliputi desain arsitektur sistem dan perangkat keras. Pada tahap ini dilakukan perancangan sistem dengan menggunakan pemodelan sistem Unified Modelling Language (UML) yaitu use case, activity diagram, class diagram dan sequence diagram. Tool yang digunakan dalam proses desain yaitu Microsoft Visio.

\subsubsection{Implementation and Unit Testing}

Pada tahap ini, sistem pertama kali dikembangkan di program kecil yang disebut unit, yang terintegrasi dalam tahap selanjutnya. Setiap unit dikembangkan dan diuji untuk fungsionalitas yang disebut sebagai unit testing. Bahasa program yang digunakan dalam sistem e-reporting ini adalah bahasa pemrograman PHP dan javascript dan MySQL sebagai DBMS (Database Management System). 


\subsubsection{Integration and System Testing}

Seluruh unit yang dikembangkan dalam tahap implementasi diintegrasikan ke dalam sistem setelah pengujian yang dilakukan masing-masing unit. Setelah integrasi seluruh sistem diuji untuk mengecek setiap kegagalan maupun kesalahan, kemudian dilakukan pengkajian ulang dan perbaikan terhadap aplikasi e-reporting menjadi lebih baik dan sempurna.

\subsubsection{Operation and Maintenance}

Perangkat lunak yang sudah jadi, dijalankan serta dilakukan pemeliharaan. Pemeliharaan termasuk dalam memperbaiki kesalahan yang tidak ditemukan pada tahap sebelumnya.

\section{HASIL DAN PEMBAHASAN}

Adapun hasil dan pembahasan dari penelitian "Rancang Bangun $E$ Reporting Pada Bagian Pelayanan PDAM Kabupaten Kuningan Berbasis Image Geotagging" adalah sebagai berikut:

\subsection{E-Reporting}

E-Reporting adalah suatu pelaporan yang disampaikan secara elektronik dengan menggunakan media elektronik. Media elektronik adalah suatu alat yang digunakan sebagai perantara untuk menginformasikan suatu hal atau masalah dalam bentuk elektronik. Media elektronik dapat berbentuk analog maupun digital. Media elektronik yang bisa dipakai untuk mengakses pelaporan ini berupa komputer dengan menggunakan jaringan intranet.[5]

\subsection{Konsep Geotagging Pada E- Reporting}

Geotagging merupakan proses penambahan informasi geospasial pada berbagai media digital. Media yang telah mengalami proses geotagging akan memiliki informasi koordinat berupa longitude (bujur), latitude (lintang) dan altitude (ketinggan). Hal tersebut memungkinkan media dapat diposisikan secara tepat pada peta.[6]

Konsep Geotagging pada EReporting yang digunakan pada sistem PDAM Tirta Kamuning Kabupaten Kuningan adalah sebagai berikut:

1. E-Reporting, pengadu melakukan pelaporan secara online menggunakan smartphone yang terhubung melalui jaringan internet.

2. Geotagging, pengambilan foto yang dilengkapi dengan fitur GPS pada kamera digital secara langsung. Ketika foto diambil dari kamera tersebut maka informasi lokasi akan secara otomatis tersimpan pada EXIF header dari hasil foto yang diambil.

3. Menampilkan lokasi berdasarkan koordinat dari data EXIF foto yang dimana koordinat tersebut dapat membantu teknisi atau perusahaan mengetahui alamat dalam maps.

\subsection{Analisis Sistem Usulan}

Flowmap atau bagan alir adalah bagan yang menunjukan aliran di dalam program atau prosedur sistem secara logika. Flowmap berfungsi untuk memodelkan masukan, keluaran, proses maupun transaksi dengan menggunakan simbol - simbol tertentu. Pembuatan flowmap ini harus dapat memudahkan bagi pemakai dalam memahami alur dari sistem atau transaksi.[7]

Sistem yang diusulkan bertujuan untuk memfasilitasi kekurangan yang terjadi pada sistem yang sedang berjalan saat ini. 


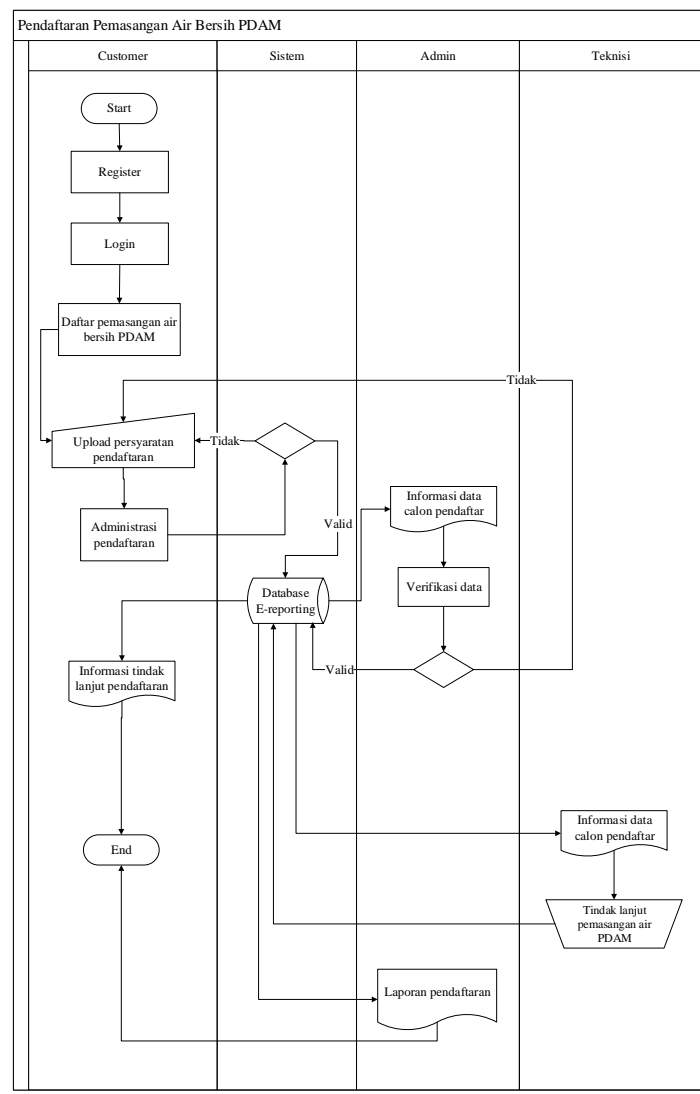

Gambar 2. Flowmap pemasangan yang diusulkan

Penjelasan gambar 2, Flowmap sistem yang diusulkan pada proses pendaftaran pemasangan air bersih PDAM :

1. Customer melakukan register agar dapat melakukan login ke sistem e-reporting.

2. Customer melakukan login untuk dapat masuk ke sistem $e$ reporting.

3. Customer melakukan pendaftaran pemasangan air bersih PDAM pada sistem $e$ reporting.

4. Customer mengupload foto KTP dan rekening air PDAM rumah terdekat yang sudah terpasang.

5. Customer melakukan transaksi pembayaran.

6. Jika data yang diinputkan oleh customer sesuai, maka sistem akan menyimpan dalam database e-reporting dan admin akan
p-ISSN : 1858-3911, e-ISSN : 2614-5405

https://journal.uniku.ac.id/index.php/ilkom

menerima informasi data customer.

7. Admin memverifikasi data customer apakah data yang diinputkan telah sesuai dengan persyaratan atau tidak.

8. Jika admin telah memverifikasi data customer maka teknisi akan mendapatkan notifikasi pendaftaran.

9. Teknisi melakukan pemasangan air bersih PDAM.

10. Customer dapat mengetahui tindak lanjut dari proses pemasangan air bersih PDAM.

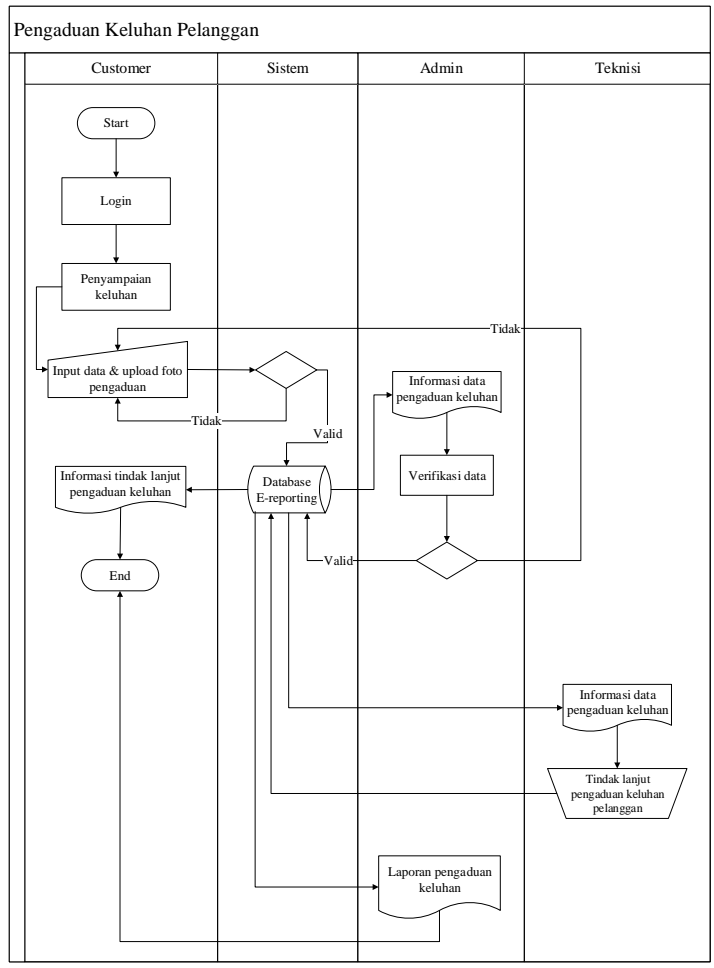

Gambar 3.Flowmap pengaduan keluhan yang diusulkan

Penjelasan gambar 3.5, Flowmap sistem yang diusulkan pada proses pengaduan keluhan :

1. Customer melakukan login terlebih dahulu untuk dapat melakukan pengaduan.

2. Customer menyampaikan pengaduan keluhan pada sistem e-reporting.

3. Customer menginputkan data serta mengupload foto kerusakan yang 
terjadi.

4. Jika data yang diinputkan oleh customer sesuai, maka sistem akan menyimpan dalam database $e$ reporting dan admin akan menerima informasi data pengaduan keluhan.

5. Admin memverifikasi data customer apakah data yang diinputkan telah sesuai dengan keterangan atau tidak.

6. Jika data yang diinputkan telah diverifikasi oleh admin, maka teknisi mendapatkan notifikasi pengaduan keluhan.

7. Teknisi menindaklanjuti pengaduan keluhan customer.

8. Customer dapat mengetahui tindak lanjut dari proses pengaduan keluhan.

\subsection{Use Case Diagram}

Use case menggambarkan bagaimana aktor berhubungan dengan sistem secara teratur, menunjukkan fungsionalitas suatu sistem bagaimana sistem berinteraksi dengan aktor. Berikut adalah use case diagram pada sistem $e$ reporting yang akan dibangun :

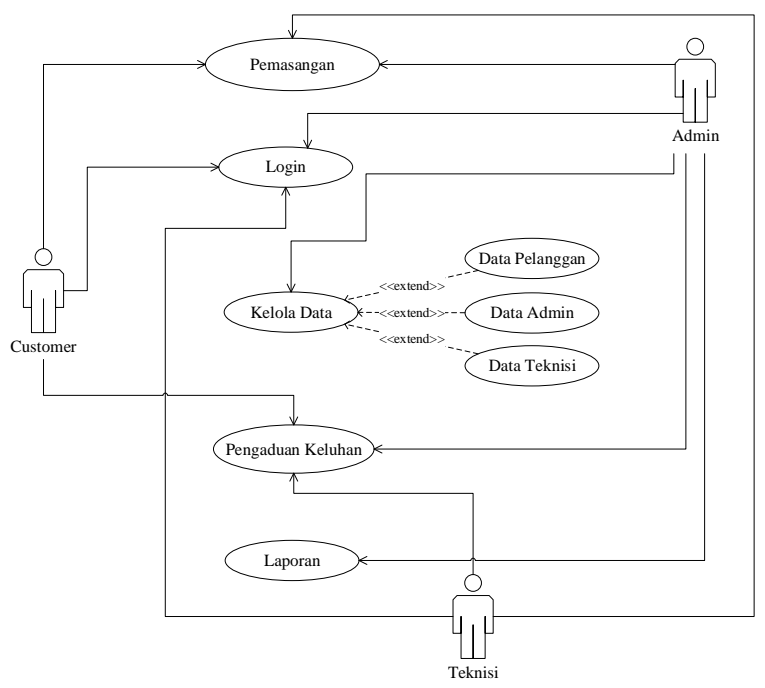

Gambar 4. Use Case Diagram
Activity diagram digunakan untuk menggambarkan alur kerja pada sistem yang akan dibangun. Diagram ini menggambarkan aktifitas yang dilakukan oleh sistem berdasarkan use case yang telah dibuat. Pada sistem $e$ reporting terdapat beberapa aktifitas, yaitu :

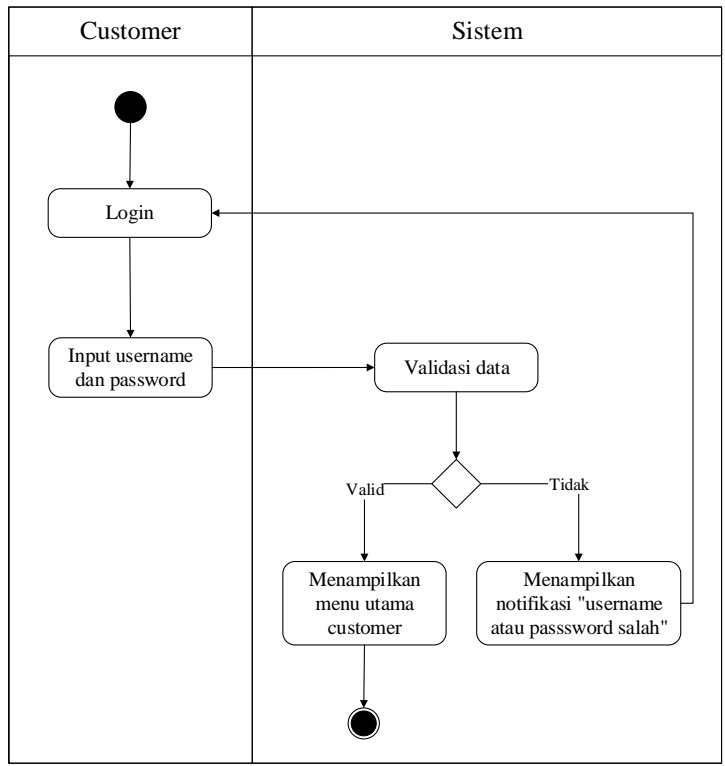

Gambar 5. Activity Diagram Login Customer

Penjelasan gambar 5, activity diagram login adalah sebagai berikut :

1. Customer menginputkan username dan password.

2. Sistem mengecek apakah data yang diinputkan customer valid atau tidak. Jika valid maka sistem menampilkan halaman utama.

\subsection{Activity Diagram}




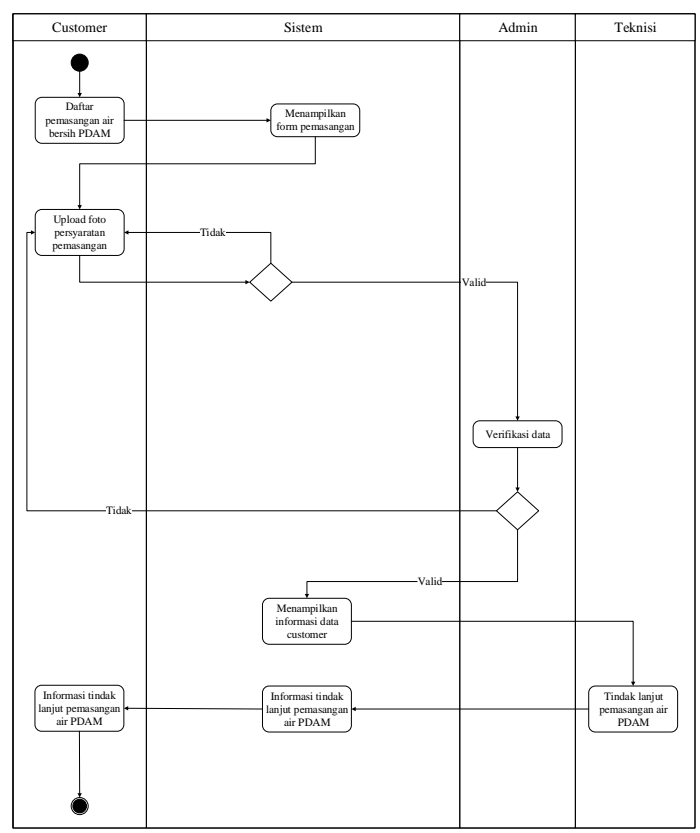

Gambar 6. Activity Diagram

Pemasangan

Penjelasan gambar 6, activity diagram pemasangan adalah sebagai berikut :

1. Customer memilih menu pemasangan.

2. Customer mengupload beberapa persyaratan.

3. Kemudian admin mengecek dan memverifikasi data tersebut.

4. Jika data telah di verifikasi oleh admin, maka teknisi akan menindaklanjuti pemasangan air PDAM.

5. Customer akan mendapatkan informasi dari proses pemasangan yang sedang ditindaklanjuti oleh teknisi.



Gambar 7. Activity Diagram Pengaduan Keluhan

Penjelasan gambar 7, activity diagram pengaduan keluhan adalah sebagai berikut :

1. Customer memilih menu pengaduan.

2. Customer menginputkan data dan mengupload persyaratan.

3. Kemudian admin mengecek dan memverifikasi data tersebut.

4. Jika data telah di verifikasi oleh admin, maka teknisi akan menindaklanjuti pengaduan keluhan.

5. Customer akan mendapatkan informasi dari proses pengqaduan yang sedang ditindaklanjuti oleh teknisi.

Berikut ini merupakan hasil implementasi dari perancangan sistem yang telah dibuat:

a. Antarmuka Register Akun

Antarmuka register akun adalah halaman yang berisi data diri customer untuk mendapatkan account. 


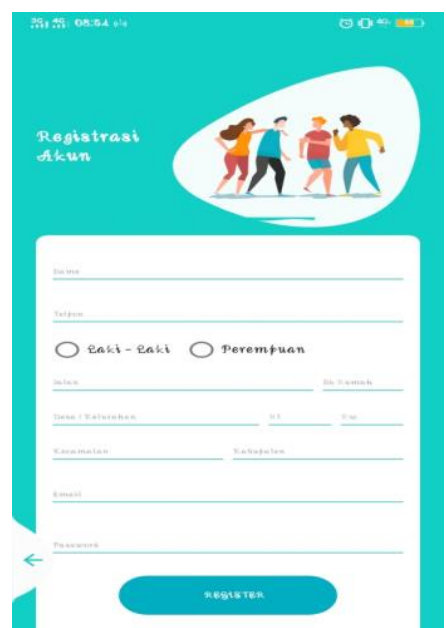

Gambar 8. Antarmuka Register

b. Antarmuka Login Customer

Antarmuka login adalah halaman customer untuk menginputkan username dan password.



Gambar 9. Antarmuka Login Customer

c. Antarmuka Halaman Utama Customer

Antarmuka halaman utama atau beranda adalah halaman yang berisi pemasangan, pengaduan, about, contact us dan beberapa lokasi cabang PDAM Tirta Kamuning Kabupaten Kuningan.
p-ISSN : 1858-3911, e-ISSN : 2614-5405

https://journal.uniku.ac.id/index.php/ilkom

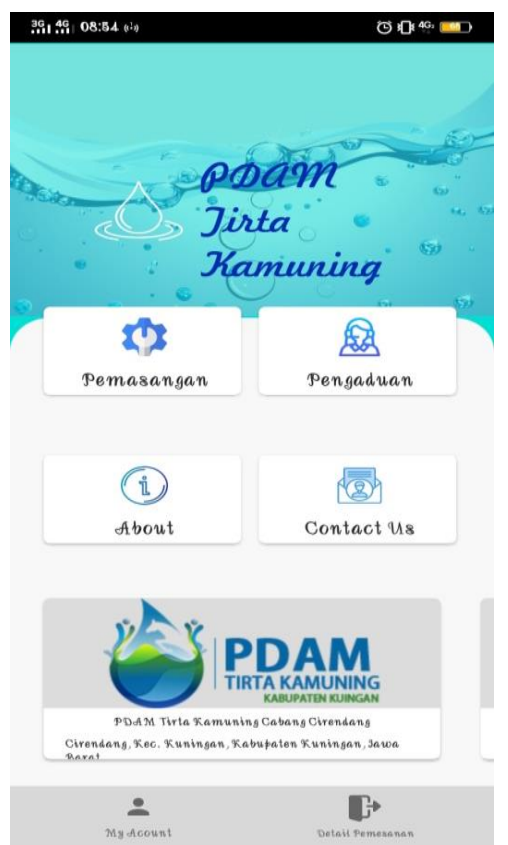

Gambar 10. Antarmuka Beranda

d. Antarmuka Detail Pemesanan

Antarmuka detail pemesanan adalah halaman yang berisi tentang informasi pemasangan dan pengaduan yang telah dilakukan oleh customer.

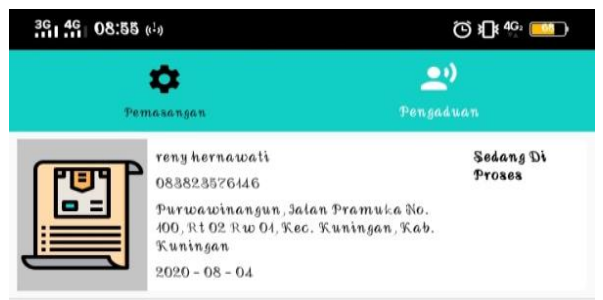

\section{Gambar 11. Antarmuka Detail Pemesanan}

e. Antarmuka Profil Customer Antarmuka my account adalah halaman yang berisi tentang data diri customer. 


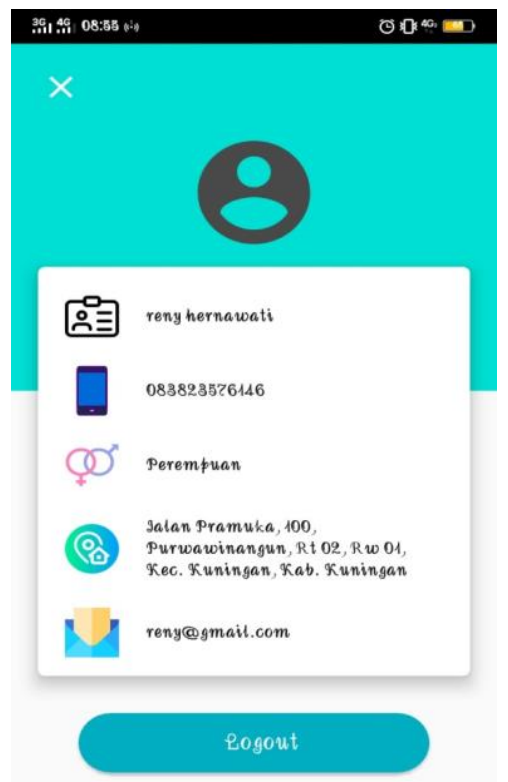

Gambar 12. Antarmuka My Account

f. Antarmuka Maps

Antarmuka maps adalah halaman yang berisi rute dari alamat yang dimasukan ketika pelanggan melakukan pemasangan air bersih PDAM atau melakukan pengaduan.

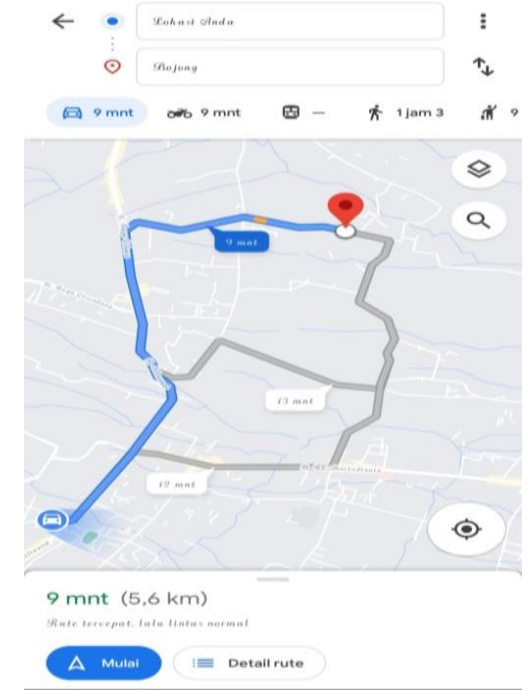

Gambar 13. Antarmuka Maps

\section{KESIMPULAN}

Berdasarkan hasil uraian yang telah dilakukan tentang Rancang Bangun $E$ Reporting Pada Bagian Pelayanan PDAM Kabupaten Kuningan Berbasis
Image Geotagging dapat ditarik kesimpulan bahwa:

1. Sistem yang dibangun memberikan informasi kepada customer mengenai sejarah PDAM Tirta Kamuning Kabupaten Kuningan.

2. Proses pelayanan customer dalam melakukan pendaftaran pemasangan air bersih PDAM dan melakukan pengaduan kebocoran pipa, air kotor, air macet dan tagihan rekening air yang membengkak lebih cepat ditangani.

3. Sistem yang dibangun dapat memberikan solusi terhadap permasalahan teknisi dalam pencarian lokasi pemasangan atau pengaduan customer.

4. Pengelolaan data customer, data admin, data teknisi dan data laporan lebih terorganisir dengan baik dalam suatu database dimana terdapat fasilitas pengolahan data input, update dan delete sehingga dapat menghemat biaya, waktu dan proses.

5. Customer dapat memberikan rating (penilaian) terhadap kinerja dari teknisi tersebut.

\section{SARAN}

Hasil dari penelitian yang dilakukan di PDAM Tirta Kamuning Kabupaten Kuningan tentunya masih memiliki kekurangan. Berikut ini beberapa saran untuk pengembangan sistem kedepannya agar sistem menjadi lebih baik, adapun beberapa saran tersebut, yaitu:

1. Pengisian data untuk semua format masukan harus dilakukan dengan teliti sehingga informasi yang dihasilkan sesuai dengan yang diharapkan.

2. Perlu adanya pengembangan dari sistem yang telah dibuat agar lebih baik, baik dari segi 
tampilan maupun pelayanan

PDAM Tirta Kamuning

Kabupaten Kuningan.

\section{DAFTAR PUSTAKA}

[1] Valli, C. 2010. Geotagging Where Cyberspace Comes to Your Place.

Lawley, WA. Australia : Edith Cowan University.

[2] Saputra, A., Herdiansyah, M. I., \& Udariansyah, D. 2019. Rancang Bangun Aplikasi E-Reporting Layanan Masyarakat Kecamatan Buay Madang Berbasis Android. Bina Darma Conference on Computer Science.

[3] Dinas Komunikasi Dan Informatika Kabupaten Kuningan. 2013. Pemerintah Kabupaten Kuningan. [Online].

Tersedia:

https://www.kuningankab.go.id/ produk-hukum/perda-tahun2013

[4] Pressman, Roger S. 2012. Rekayasa Perangkat Lunak - Buku Satu, Pendekatan Praktisi (Edisi 7). Yogyakarta: Andi.

[5] Firmansyah, Hasrul. 2013. Rancang Bangun E-Reporting Modul Bidang Penyuluhan Pada Dinas Pertanian Kabupaten Jombang.

[6] Joshi, D., Gallagher, A., Yu, J. \& Luo, J., 2010. Exploring User Image Tags for GeoLocation Inference. s.l.:s.n.

[7] Shalahudin, M., \& Rosa, A. S. 2015. Rekayasa Perangkat Lunak Terstruktur dan Berorientasi Objek. Bandung : Informatika. 